\title{
Water Hammer Caused by Rapid Gas Production in a Severe Accident in a Light Water Reactor*
}

\author{
Fujio INASAKA**, Masaki ADACHI ${ }^{* *}$, Kohki SHIOZAKI ${ }^{* * *}$, \\ Izuo AYA $^{* * * *}$ and Hideki NARIAI ${ }^{\dagger}$
}

\begin{abstract}
We investigated the water hammer caused by striking of water mass pushed up by a rapidly growing bubble and its scale effects using two cylindrical model containment vessels of 1.0 and $0.428 \mathrm{~m}$ diameters. We also closely observed the movement of water mass and the growing bubble in the vessels. In these experiments, rapid bubble growth was simulated by injecting high-pressure air into a water pool. It was clarified that the water mass was pushed up without any air penetration until the water level reached a certain elevation. On the basis of all data, experimental correlations for estimating the height and striking velocity of the water mass with coherency were proposed, and the water hammer pressure for exerting large forces on the structures was quantitatively evaluated.
\end{abstract}

Key Words: Water Hammer, LWR, Severe Accident, Steam Explosion, Bubble Growth, Water Pool, Containment Vessel, Water Mass, Coherent Movement

\section{Introduction}

It has long been recognized that it is important to establish preventive measures and accident management procedures for a severe accident in a light water reactor (LWR) after we experienced the Three Mile Island and Chernobyl accidents ${ }^{(1)-(3)}$. In a severe accident in an LWR, it is supposed that a large amount of gas is rapidly generated at the bottom of a water pool in a containment vessel due to water-metal reaction or steam explosion. Rapid bubble growth, caused by the water mass being pushed up with coherency in time and direction of its movement, would result in a severe water hammer in the structures in the containment vessel.

The possibility of ex-vessel steam explosion, an explosion outside of the reactor pressure vessel due to the fuel-coolant interaction (FCI), cannot be completely negligible when a water pool exists at the bottom floor of a containment vessel ${ }^{(4)}$; thus, numerous large-scale FCI experi-

* Received 26th July, 2004 (No. 04-4170)

** Maritime Safety Department, National Maritime Research Institute, 6-38-1 Shinkawa, Mitaka, Tokyo 181-0004, Japan. E-mail: inasaka@nmri.go.jp

*** Once, National Maritime Research Institute

**** Osaka Branch, National Maritime Research Institute, 35-10 Amanogahara, Kitano, Osaka 576-0034, Japan

$\dagger$ The University of Tsukuba Professor Emeritus, 2-34-9 Umezono, Tsukuba, Ibaraki 305-0045, Japan ments with corium have been conducted in various countries in the past decade ${ }^{(5)-(8)}$. Among them, in the experiment conducted at the Korea Atomic Energy Research Institute $^{(8)}$, spontaneous steam explosion occurred, and the maximum dynamic force on the bottom wall of the test section was measured to be $250 \mathrm{kN}$. However, there are few experimental studies on the behavior of water mass pushed up by a growing bubble, although several reports pointed out the direct impact of a pressure wave by the FCI. In particular, no studies for systematically evaluating the water hammer caused by a growing bubble have been reported.

In this study, we aim at experimentally clarifying the occurrence condition of the water mass movement with coherency and propose a quantitative evaluation method for the water hammer that may exert large forces on the structure in a containment vessel. In this paper, we report the experimental data of the water hammer occurring in the two cylindrical model containment vessels, the observation images of single-bubble growth, and a quantitative evaluation method for this type of water hammer.

\section{Nomenclature}

$A$ : Dimensionless constant in Eq. (5) [-]

$a$ : Acceleration of rising water $\left[\mathrm{m} / \mathrm{s}^{2}\right]$

$B$ : Dimensionless constant in Eq. (6) [-]

$D$ : Inside diameter of model containment vessel [m]

$g:$ Gravitational acceleration $\left[\mathrm{m} / \mathrm{s}^{2}\right]$ 
$H$ : Water surface level from air outlet [m]

$H^{*}$ : Dimensionless water surface level from air outlet $(=H / D)[-]$

$H_{0}$ : Initial level of water pool from air outlet [m]

$H_{0}^{*}$ : Dimensionless initial level of water pool (= $\left.H_{0} / D\right)[-]$

$H_{P}$ : Water surface level at bubble penetration time [m]

$H_{P}^{*}$ : Dimensionless water surface level at bubble penetration time $\left[=\left(H_{P} / D\right)\right][-]$

$\Delta H_{P}$ : Rising distance of water surface at bubble penetration time $\left[=\left(H_{P}-H_{0}\right)\right][\mathrm{m}]$

$\Delta H_{P}^{*}$ : Dimensionless rising distance of water surface at bubble penetration time $\left[=\left(H_{P}-H_{0}\right) / D\right][-]$

$P_{0}$ : Initial injection air pressure $[\mathrm{Pa}]$

$P_{0, m}$ : Reference value of $P_{0}$ in Eqs. (8) and (9) [Pa]

$P_{12 M A X}:$ Maximum transducer pressure, PT12 [Pa]

$P_{a m b}:$ Atmospheric pressure $[\mathrm{Pa}]$

$P_{W H}:$ Water hammer pressure $[\mathrm{Pa}]$

$P_{W H, M A X}:$ Maximum water hammer pressure $[\mathrm{Pa}]$

$\Delta P_{0}$ : Differential pressure $\left(=P_{0}-P_{a m b}\right)[\mathrm{Pa}]$

$\Delta P_{0}^{*}$ : Dimensionless differential pressure in Eq. (7) [-]

$\Delta P_{0, m}:$ Variable in Eq. (11) $[\mathrm{Pa}]$

$t$ : Time [s]

$t_{P}:$ Bubble penetration time $[\mathrm{s}]$

$u$ : Rising velocity of water surface $[\mathrm{m} / \mathrm{s}]$

$u_{P}$ : Rising velocity of water surface at bubble penetration time $[\mathrm{m} / \mathrm{s}]$

$\rho$ : Density of water mass $\left[\mathrm{kg} / \mathrm{m}^{3}\right]$

$\eta$ : Variable in Eq. (10) $\left[\mathrm{m}^{2} / \mathrm{s}^{2}\right]$

\section{Experiment}

\subsection{Experimental apparatus}

Two cylindrical model containment vessels of 1.0 and $0.428 \mathrm{~m}$ diameters were used in the experiment. In this paper, these vessels are called "the large vessel" and "the small vessel". The small vessel was manufactured for clarifying the scale effect of the vessel on the water mass movement and for closely observing the growth of a single bubble that determines the behavior of a water hammer. Rapid bubble growth was simulated by injecting high-pressure air into the water pool in the vessel.

\subsubsection{Large vessel Figure 1 shows the schematic} view of the large vessel. The model containment vessel is cylindrical and has a diameter of $1.0 \mathrm{~m}$ and a height of $6 \mathrm{~m}$. After setting a glass plate at the air outlet, the lower part of the vessel was filled with water up to the intended initial level, and then the air tank and the air supply pipe were filled with high-pressure air. The diameters of the air supply pipe and the air outlet are $0.15 \mathrm{~m}$. This value was determined to be sufficiently large for supplying air, such that the growing velocity of a bubble should exceed the estimated terminal velocity of a bubble of $1 \mathrm{~m}$ diameter in water. The volume of air $\left(0.47 \mathrm{~m}^{3}\right.$, including the air supply pipe) injected into the water pool in the large

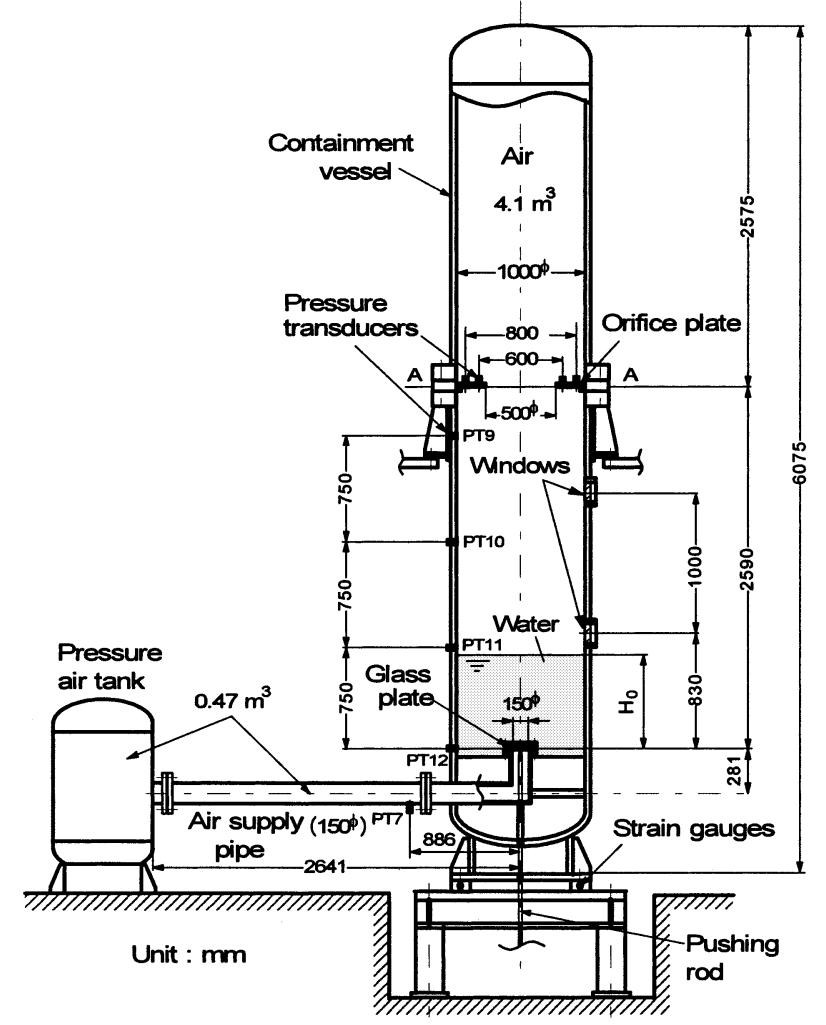

Fig. 1 Schematic view of the large vessel

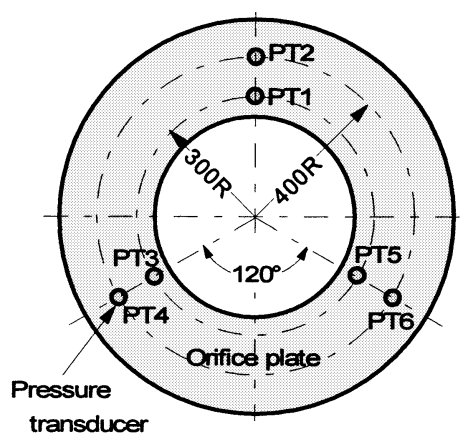

Fig. 2 Locations of pressure transducer installed in the orifice plate

vessel was determined, assuming that the steam is produced by the specific heat of about $11 \mathrm{~kg}$ of corium, the mass of which corresponds to 11 tons of corium in a real reactor. The scale ratio of the large vessel to an actual reactor was assumed to be $1 / 10$. Upon breaking the glass plate instantaneously with a pushing rod, the injection of air into the water pool was started. The space above the water surface was maintained at an atmospheric pressure until the air was injected. An orifice plate (opening diameter: $0.5 \mathrm{~m}$ ), which simulates the structure in the containment vessel, was installed in the middle of the vessel. As shown in Fig. 2, six pressure transducers (PT1-6) were set on the lower surface of the orifice plate to measure the water hammer pressure on it. Pressure transducers were also set on the side wall of the vessel (PT9-12) and in the air 
supply pipe (PT7). At the foot of the vessel, four strain gauges were fixed to measure the total load exerting on the vessel. These measuring signals were stored in a personal computer with a sampling time of $50 \mu$ s through A/D converters and amplifiers. The movement of the water mass was photographed using a high-speed camera (250 or 500 FPS) through the circular observation window.

\subsubsection{Small vessel Figure 3 shows the schematic} view of the small vessel. Its scale ratio to the large vessel is $428 / 1000$, with the exception of the position of the air tank, the shape of the observation window (narrow and long rectangle) and adding a pressure transducer (PT17) at the top of the vessel. The experiment for observing bubble growth was conducted by changing the lower part of the vessel with an acrylic tube.

\subsection{Experimental conditions}

If the bubble grows from the air outlet keeping the same shape irrelevantly to the scales, the relative water level at the air penetration position would be independent of the size of the vessel and be decided by the aspect ratio of the initial water level from the air outlet, $H_{0}$, and vessel diameter, $D$. Therefore, dimensionless water level, $H_{0}^{*}=$ $H_{0} / D$, and initial injection air pressure, $P_{0}$, were selected

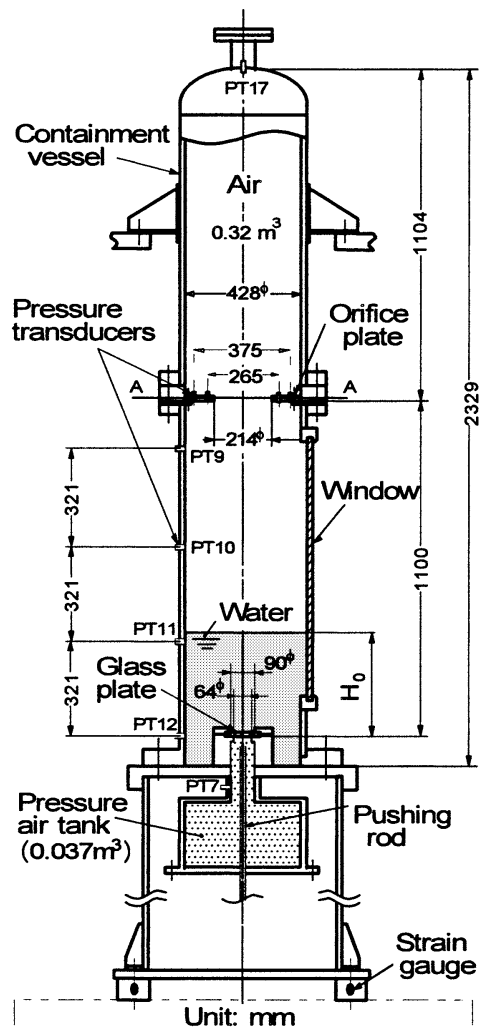

Fig. 3 Schematic view of the small vessel

Table 1 Experimental conditions

\begin{tabular}{|l|c|}
\hline Initial injecting air pressure, $P_{0}[\mathrm{MPa}]$ & $0.5,1.0,2.0$ \\
\hline Dimensionless water level, $H_{0}{ }^{*}=H_{0} / D$ & $0.6,0.8,1.0,1.2,1.4$ \\
\hline
\end{tabular}

as the parameters as shown in Table 1.

The force exerting on the structure, when the water mass accelerated by a rapidly growing bubble would directly strike the orifice plate with high coherency of movement, was expected to be very large, such that the apparatus could not resist. Thus, the experimental conditions were selected in the region where a growing bubble penetrates the water surface at a level below the orifice plate. Then the experiments were conducted under less severe conditions than those in which severe damage is expected. In fact, severe damage occurred at $P_{0}=2.0 \mathrm{MPa}$ and $H_{0}^{*}=1.2$ in both the large and small vessels. Experiments at $H_{0}^{*}=0.9$ and 1.1 , and $P_{0}<0.5 \mathrm{MPa}$ were also conducted for the small vessel in order to examine the effect of such parameters in detail.

\section{Experimental Results and Discussions}

\subsection{Observation of bubble growth}

Figure 4 shows the images of the growing bubble obtained at 500 FPS using a high-speed camera in the experiment conducted at $P_{0}=0.5 \mathrm{MPa}$ and $H_{0}^{*}=0.6$. In the figure, the air injection starting time corresponds to $0 \mathrm{~ms}$. The bubble grows by almost keeping the semi-ellipsoid shape in both the width and height directions until its width reaches the vessel diameter, and then it begins to grow rapidly in the upward direction. The water surface is piston-likely pushed up, while keeping it in the horizontal direction for a while. However when the top of the bubble reaches near the water surface, the center of the water surface is conically lifted by the growing bubble, and then the bubble begins to penetrate the water surface. As soon as the bubble penetrates the water surface, the mixture of air and water droplets (called "the water mass group") splashes upward. The lifting phenomenon of the center surface was observed only in the small vessel. In the large vessel, the water surface is pushed up, while keeping it in the horizontal direction until the bubble penetrates the water surface. The increase in wall friction with the decrease in vessel diameter might cause this peculiar phenomenon in the small vessel. As reported in the published paper on a single bubble in a vertical tube ${ }^{(9)}$, the increase in viscosity increases the quantity of the falling water, which was observed to be higher in the lower part of the bubble than in its upper part (refer to the image obtained after $16 \mathrm{~ms}$ in Fig. 4), and sharpens the tip of the bubble to be wedgelike.

When paying attention to the bubble interface, some disturbance waves with small ruggedness can be seen. Figure 5 shows the bubble volume transient ( $\square$ ) calculated from the bubble images in Fig. 4 and the transient of gas phase quantity $(0)$ calculated from the changes in water level, assuming that the initial water quantity is constant. In all data of bubble observations, the gas phase quantity is smaller than the bubble volume. This difference is difficult to be explained only using the ruggedness of the bubble 


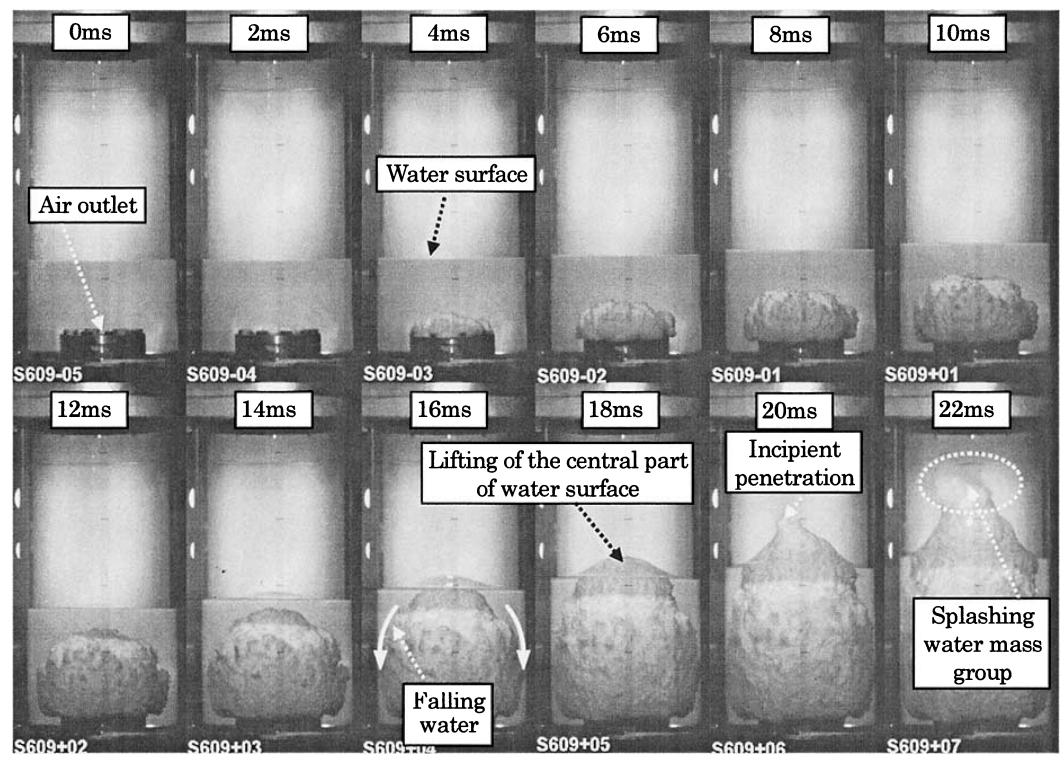

Fig. 4 Images of growing bubble $\left(P_{0}=0.5 \mathrm{MPa}, H_{0}^{*}=0.6,500 \mathrm{FPS}\right)$

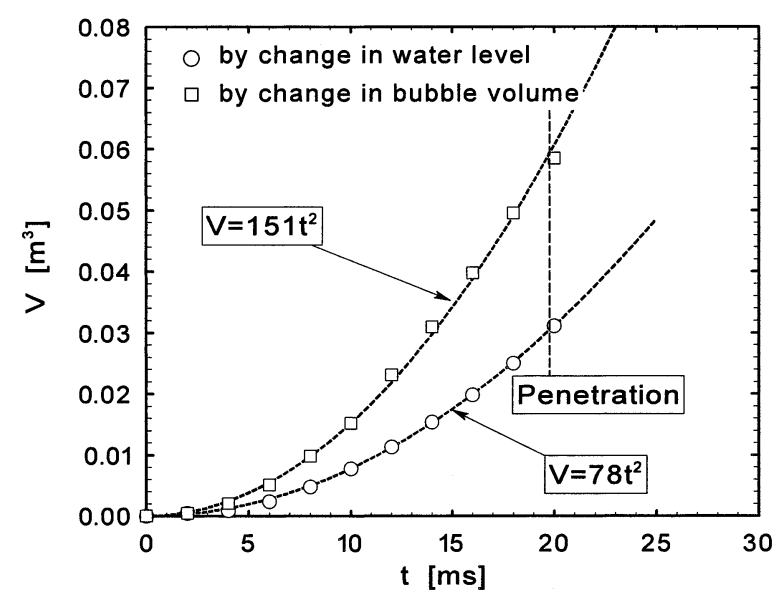

Fig. 5 Comparison of transients of bubble volume and gas phase quantity (in case of Fig. 4)

surface. The strongly disturbed interface suggests that numerous droplets should be rolled in the large bubble and the initial quantity of water single phase decreases with bubble growth.

\subsection{Experiment of water hammer using large ves-} sel

Figure 6 shows a set of images of water interface movement taken at 250 FPS using the high-speed camera at $P_{0}=2.0 \mathrm{MPa}$ and $H_{0}^{*}=1.2$. The camera angle was set so that the water surface can be peeked through the upper window. The level markers of $10 \mathrm{~cm}$ pitch were drawn on the opposite side inner wall in order to measure the transient of the water surface level. The water surface line contacting the vessel wall is shown by a broken line in the figure. It is shown that the water surface is pushed up with coherency and kept in the horizontal direction until the bubble penetrates the water surface at $40 \mathrm{~ms}$.

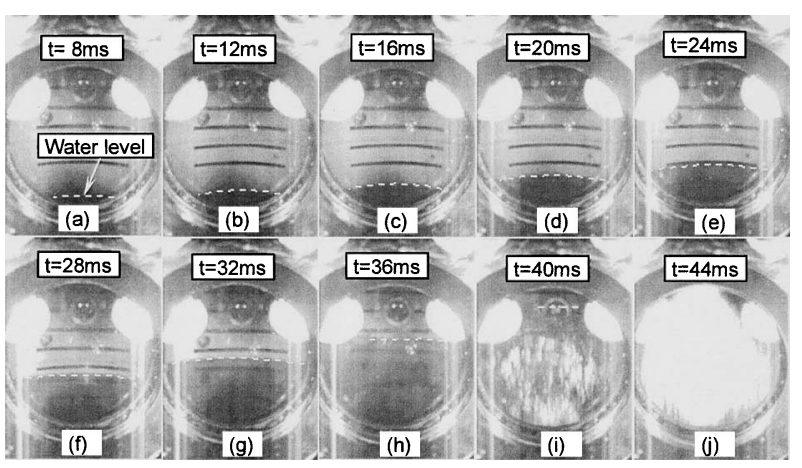

Fig. 6 Acceleration of water mass $\left(P_{0}=2.0 \mathrm{MPa}, H_{0}^{*}=1.2\right.$, large vessel)

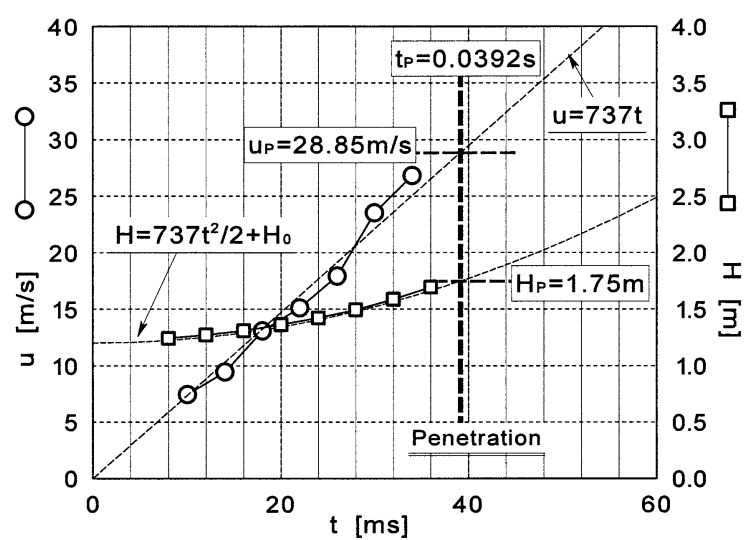

Fig. 7 Transients of water surface level and its rising velocity (in Fig. 6)

Figure 7 shows the transients of the water surface level, $H(\square)$, and the water surface rising velocity, $u(\circ)$, in the case shown in Fig. 6. As shown in the figure, the rising velocity can approximately be expressed by a straight line. This indicates that the acceleration of the water surface, $a$, 
is almost constant (about $737 \mathrm{~m} / \mathrm{s}^{2}$ in this case), and that $H$ and $u$ can be estimated by

$$
\begin{aligned}
& H=\frac{a}{2} t^{2}+H_{0}, \\
& u=a t .
\end{aligned}
$$

It has been clarified that the acceleration of water surface in both the large and small vessels is constant within the range of experimental conditions. Since the gas space above the water pool in the vessel is closed (initially at an atmospheric pressure), the space is compressed by the rise of the water surface and its pressure, which prevents the acceleration of the water mass, increases. In our experiment, the acceleration of the water surface seems to be almost constant. This may be explained by the fact that the decrease in water mass being pushed up by the growing bubble is almost the same as the above-mentioned compression effect by the increased gas pressure above the water surface. However, at $P_{0} \leq 0.3 \mathrm{MPa}$ in the small vessel, the effect of compression became significant and a certain deceleration effect on the rising water was observed. The vertical broken line in Fig. 7 shows the time at which the bubble penetrates the water surface. The penetration time was determined from the images obtained using the high-speed camera, referring to the transient of the pressure transducer. The level, $H_{P}$, and rising velocity, $u_{P}$ of the water surface at the penetration time were determined when Eq. (1) or (2) reaches the penetration time, respectively. In this case, $H_{P}=1.75 \mathrm{~m}$ and $u_{P}=28.85 \mathrm{~m} / \mathrm{s}$. It is shown that the water mass with coherency is accelerated and pushed up by $0.55 \mathrm{~m}$ until the bubble penetrates the water surface.

Figure 8 shows the relationship among the transient data measured at various points of the vessel in Figs. 6 and $7\left(P_{0}=2.0 \mathrm{MPa}, H_{0}^{*}=1.2\right)$. Figure 8 (a) shows the water hammer pressure (PT1-6) on the orifice plate. Figure 8 (b) shows the pressure in the air supply pipe (PT7) and those on the sidewall of the vessel (PT9-12). Figure 8 (c) shows the total load exerting on the vessel measured at the foot of the vessel. A vertical broken line in the figure represents the penetration time.

The subfigure with an expanded time scale is also added in Fig. 8 (a). This is the case in which the largest water hammer was generated for the large vessel. As shown in Fig. 8 (a), the water mass group strikes the orifice plate at about $25 \mathrm{~ms}$ after the bubble penetration. The water hammer pressure at this time reaches more than $10 \mathrm{MPa}$, 5 times the initial injection air pressure. Because the pressure exceeded the measurement range of $10 \mathrm{MPa}$ in the case of PT3, the pressure peak is cut off. PT3 was then broken, so the response after that deviates. There are time lags among the pressure peaks of PT1-6, and the maximum pressures are also considerably different. It can be presumed that the initially single water mass is broken up into small pieces which strike the orifice plate with
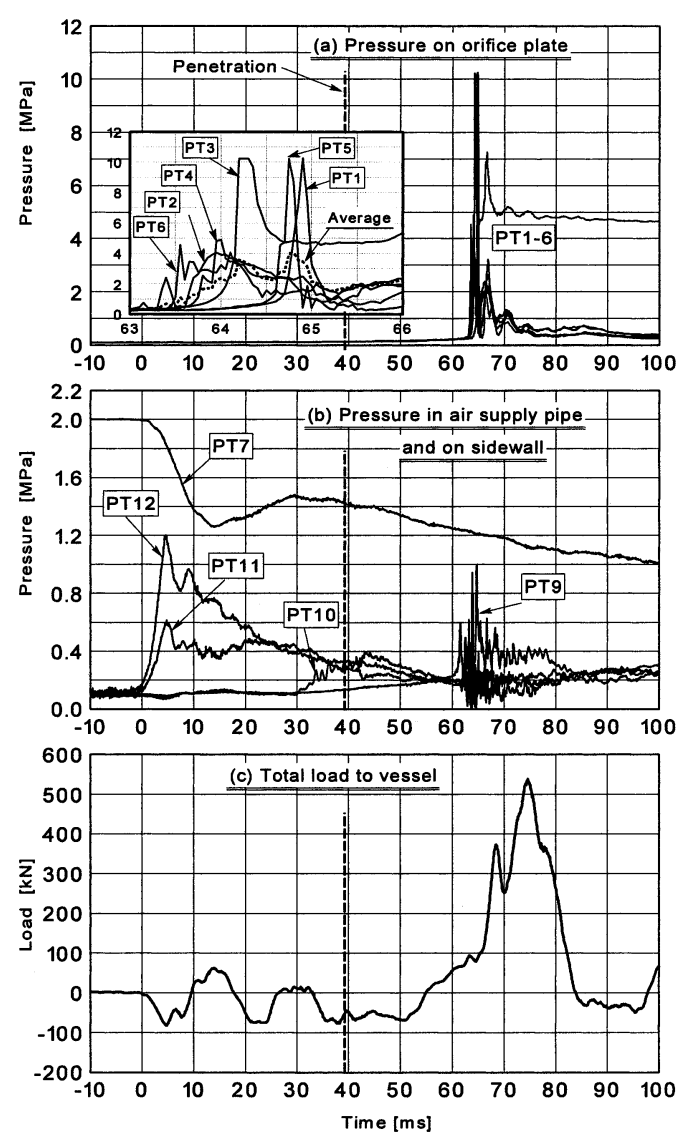

Fig. 8 Transient data measured at various points of vessel (in Figs. 6 and 7)

some time lags. Therefore, it is not easy to quantitatively evaluate the water hammer force generated by small water masses striking the orifice plate. The dotted line in the expanded subfigure is the pressure calculated by averaging the pressures of PT1-6. Its peak is about $4.0 \mathrm{MPa}$ which results in the load of about $2230 \mathrm{kN}$ by multiplying the orifice area. The water rising velocity at the penetration time $u_{P}$ in this case is $28.85 \mathrm{~m} / \mathrm{s}$ as shown in Fig. 7 . Assuming that the structure is located at the height of the bubble penetration, the water hammer pressure $P_{W H}$ which has a potential of exerting on the structure, is estimated about $40 \mathrm{MPa}$ by the following water hammer equation to be applied in a pipe.

$$
P_{W H}=\rho c u_{P}
$$

Where, $\rho$ is the density of water $\left(998.3 \mathrm{~kg} / \mathrm{m}^{3}\right)$ and $c$ is the sonic speed in water $(1438 \mathrm{~m} / \mathrm{s})$. The measured maximum water hammer pressure at the orifice was $10 \mathrm{MPa}$, about $25 \%$ of $P_{W H}$. The difference partly comes from the fact that the velocity of the water mass group decreases as it reaches the orifice. However, the main reasons are as follows. $c$ in Eq. (3) should be considerably low because many small bubbles are involved in each water mass. In addition, the water mass group breaks into pieces differently from the water hammer in a pipe where the whole space is filled with water. Therefore, the small water mass 
group will be squashed and will spread horizontally as it strikes the orifice plate. Thus, the measured pressure becomes lower than that obtained using Eq. (3). The important thing is that the water hammer pressure induced by striking the water mass group has a potential of exceeding the initial air pressure, which suggests a dangerous aspect of this type of water hammer.

In Fig. 8 (b), the pressure transient in the air supply pipe PT7 rapidly decreases from $2.0 \mathrm{MPa}$ and recovers somewhat at approximately $40 \mathrm{~ms}$ after the air injection due to the pressure wave coming from the vessel. PT11 and PT12 which initially locate in the water show a rapid pressure increase followed by air injection and have several shock waves coming from the air supply line. PT12 locates at the same elevation as the air outlet and its maximum pressure reaches about $60 \%$ of $P_{0}$. However, PT10, which locates above the initial water surface, begins to increase when the water surface reaches it at approximately $t=30 \mathrm{~ms}$.

In Fig. 8 (c), it is shown that the maximum load of about $540 \mathrm{kN}$ is exerted on the whole vessel with about $10 \mathrm{~ms}$ delay, after the water mass group strikes the orifice plate. The load data also shows a few oscillatory reaction forces during the air injection period. The total load is about $25 \%$ of $2230 \mathrm{kN}$, estimated from the averaged water hammer pressure on the orifice plate. This difference is due to an elastic deformation of structures between the orifice plate and the load transducer. However, the integrated impulse (momentum change) should be the same as that at the orifice plate.

\subsection{Experiment of water hammer using small ves-} sel

Figure 9 shows the images of the water mass movement photographed at 500 FPS by the high-speed camera under the conditions of $P_{0}=2.0 \mathrm{MPa}$ and $H_{0}^{*}=1.2$. The images at $0-14 \mathrm{~ms}$ show how the water mass is accelerated in the air space above the water surface by a growing

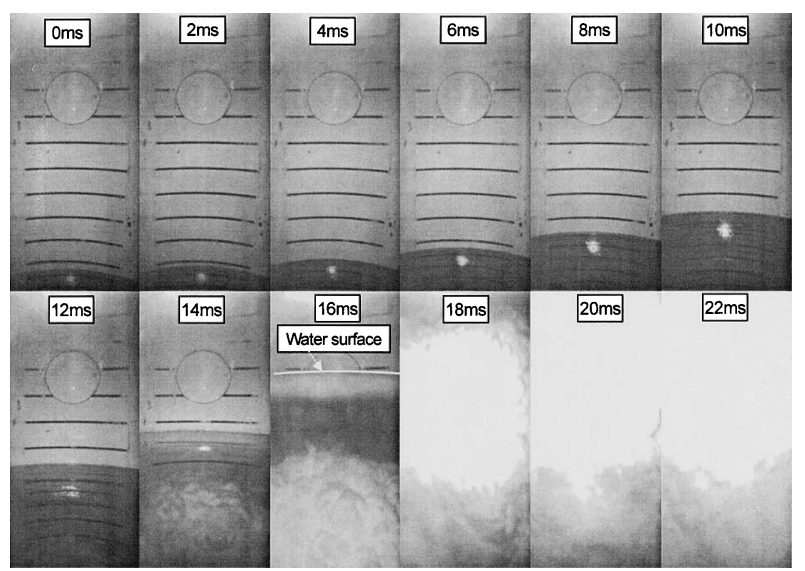

Fig. 9 Acceleration of water mass $\left(P_{0}=2.0 \mathrm{MPa}, H_{0}^{*}=1.2\right.$, small vessel) bubble. At $16 \mathrm{~ms}$, the water surface reaches the observation window and many small waves are seen at the bubble interface. The images at $18-22 \mathrm{~ms}$ show the bubble after the water interface reaches a position above the observation window. Figure 10 shows the pressure transients at the orifice plate in Fig. 9. The peak pressure of PT2 shown in the time-elongated subfigure reaches about $18 \mathrm{MPa}$ by the striking of the water mass group after the bubble penetration and the peak of the averaged pressure of PT1-6 (dotted line) reaches about $6 \mathrm{MPa}$.

\subsection{Scale effect of vessel and evaluation of water hammer}

Figure 11 shows the dimensionless rising distance of the water surface until the bubble penetrates the water surface $\Delta H_{P}^{*}=\left(H_{P}-H_{0}\right) / D$ for both large and small vessels. The abscissa is the dimensionless initial level of water pool $\left(=H_{0} / D\right), H_{0}^{*} . \circ, \triangle$ and $\square$ correspond to the initial injection air pressures $P_{0}=0.5,1.0$ and $2.0 \mathrm{MPa}$ in the large vessel, and,$+ \times$ and $i$ correspond to the same pressures in the small vessel, respectively. Since the bubble penetrates the water surface earlier at low water levels, $\Delta H_{P}^{*}$ seems to be small and almost independent of $P_{0}$. However $\Delta H_{P}^{*}$ increases with $H_{0}^{*}$ when $H_{0}^{*}$ is between $0.6-1.0$. It has a peak value at $H_{0}^{*} \approx 1.0-1.2$. At higher water levels, $\Delta H_{P}^{*}$ decreases with $H_{0}^{*}$ since the mass of water also in-

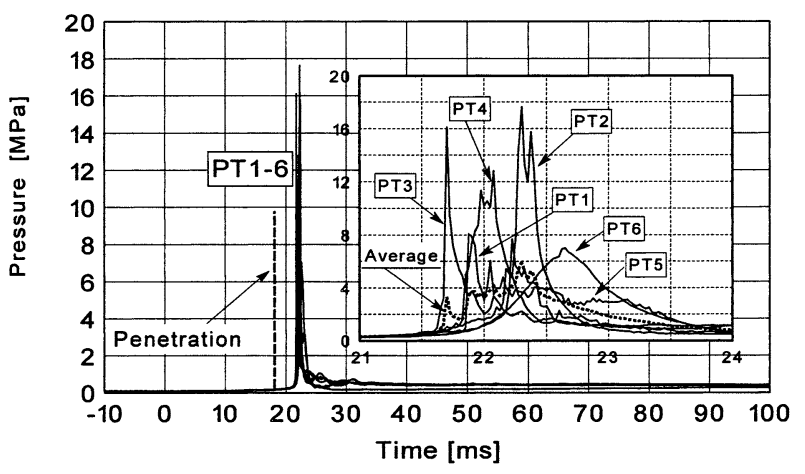

Fig. 10 Pressure transients at orifice plate (in Fig. 9)

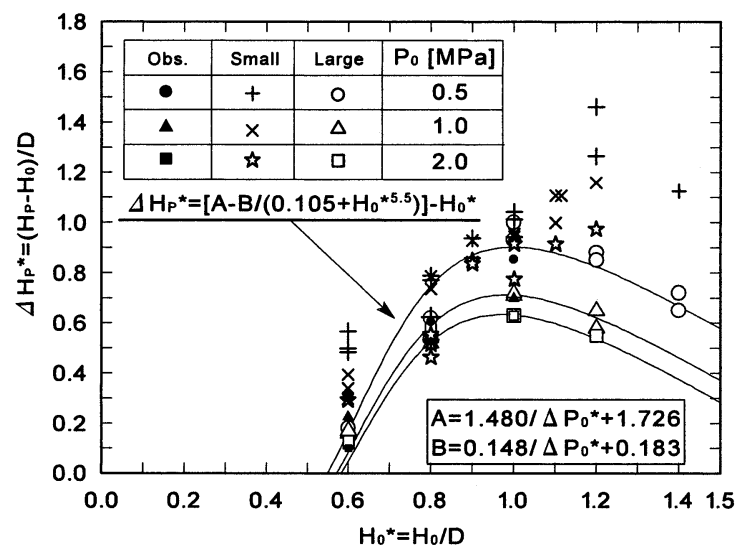

Fig. 11 Dimensionless rising distance of water surface until bubble penetrates (large and small vessels) 
creases when the water level increases. For the large vessel $(D=1 \mathrm{~m}), \Delta H_{P}^{*}$ has a peak near $H_{0}^{*}=1.0$ and the water mass is pushed up by about $0.6-1.0 \mathrm{~m}$ with coherency for $P_{0}=2.0-0.5 \mathrm{MPa}$. With regard to the effect of $P_{0}, \Delta H_{P}^{*}$ increases with a decrease in $P_{0}$. This tendency is more conspicuous at high water levels. In comparison with the data of large and small vessels, $\Delta H_{P}^{*}$ of the former is generally smaller than the latter and the tendency is higher at high water levels. Moreover, for the small vessel, $\Delta H_{P}^{*}$ increases further than that for the large vessel since the penetration occurs after the lifting of the central part of the water surface, as shown in Fig. 4. Figure 11 also shows the observed water surface levels, i.e., $\bullet, \mathbf{\Lambda}$, and $\mathbf{\square}$, when the top of the bubble reaches the water surface. Though the data points are limited, they agree well with those for the large vessel even disregarding the phenomenon that the penetration starts after the lifting of the central part of the water surface for the small vessel. That is, assuming that the water mass rises with perfect coherency when the water surface is kept horizontal during its being pushed up, we can get the following experimental correlations of $\Delta H_{P}^{*}$ with perfect coherency for both large and small vessels (represented by three solid lines in Fig. 11).

$$
\begin{aligned}
& \Delta H_{P}^{*}=A-\frac{B}{0.105+H_{0}^{* 5.5}}-H_{0}^{*} \cap \Delta H_{P}^{*}>0 \\
& A=\frac{1.480}{\Delta P_{0}^{*}}+1.726 \\
& B=\frac{0.148}{\Delta P_{0}^{*}}+0.183 \\
& \Delta P_{0}^{*}=\frac{P_{0}-P_{a m b}}{P_{\text {amb }}}
\end{aligned}
$$

Where, $P_{a m b}$ is the atmospheric pressure. Equations (4)(7) also imply that the rising distance of the water mass is almost independent of $P_{0}$ above 5.0 MPa.

The acceleration force of $\left(P_{0}-P_{a m b}-\rho g H_{0}\right)$ pushes up the water mass with a constant acceleration. Since the length of the air supply pipe is much different between the large and small vessels, as shown in Figs. 1 and 3, the delay times in the two vessels are also different. Therefore, the transient maximum value of the pressure transducer PT12 installed at the same elevation as the air outlet, $P_{12 M A X}$, was selected as the reference $P_{0}$. In this study, the following averaged $P_{0, m}$ was applied because $P_{12 M A X}$ has a large dispersion.

$$
\begin{array}{ll}
P_{0, m}=0.616 P_{0} & \text { for large vessel } \\
P_{0, m}=0.938 P_{0} & \text { for small vessel }
\end{array}
$$

Using Eqs. (8) and (9), the equation of motion of the water mass can be expressed as

$$
\begin{aligned}
& \eta=\frac{\left(\Delta P_{0, m}-\rho g H_{0}\right) \Delta H_{P}}{H_{0} \rho} \propto u_{P}^{2} \\
& \Delta P_{0, m}=P_{0, m}-P_{a m b} \\
& \Delta H_{P}=H_{P}-H_{0},
\end{aligned}
$$

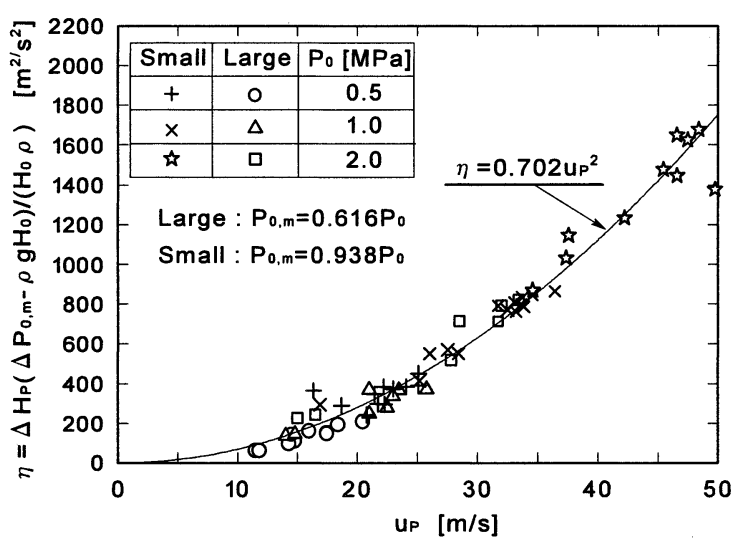

Fig. 12 Relationship between $\eta$ and $u_{P}$ of large and small vessels

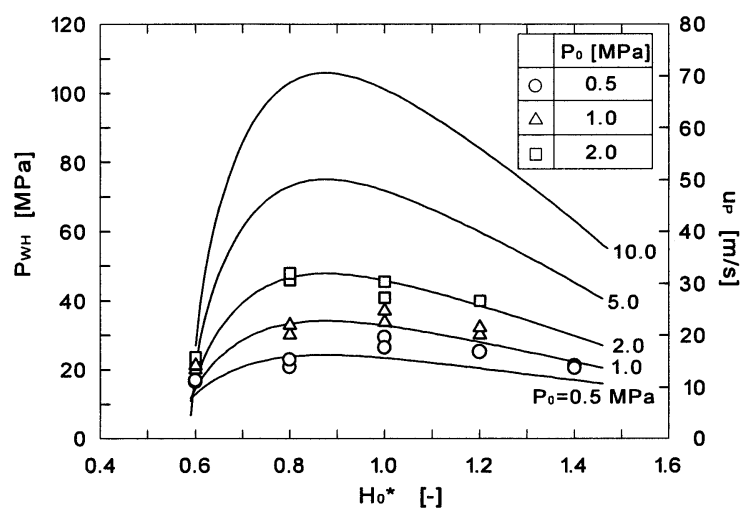

Fig. 13 Water hammer pressure evaluated by $u_{P}$ from correlation and experiment (large vessel)

where $g$ is the gravitational acceleration. The relationship between $\eta$ and $u_{P}$ for the large and small vessels is shown in Fig. 12. In this figure, $\circ, \Delta$ and $\square$, and,$+ \times$ and 25 represent the data of the large and small vessels, respectively. The ranges of $u_{P}$ for the large and small vessels are $10-35 \mathrm{~m} / \mathrm{s}$ and $20-50 \mathrm{~m} / \mathrm{s}$, respectively. The curve in the figure is the proposed experimental correlation expressed by

$$
\eta=0.702 u_{P}^{2}
$$

Using $\Delta H_{P}=a t_{P}^{2} / 2$ and $u_{P}=a t_{P}$, Eq. (13) can be transformed to

$$
a=0.712 \frac{\left(\Delta P_{0, m}-\rho g H_{0}\right)}{H_{0} \rho} .
$$

The rising velocity of the water mass reaches maximum at the bubble penetration time. The water hammer pressure calculated using Eq. (3) $\left(P_{W H}=\rho c u_{P}\right)$ exerts on the structure, if the structure is located at the position of the bubble penetration. Figure 13 shows the $P_{W H}$ calculated from correlation (13) for $P_{0}=0.5-10 \mathrm{MPa}$ (solid lines) and the $P_{W H}$ evaluated from the experimental data of $u_{P}$ for the large vessel (each symbol). The right ordinate shows the summary of $u_{P}=P_{W H} /(\rho c)$ for $\rho=1000 \mathrm{~kg} / \mathrm{m}^{3}$ and $c=1500 \mathrm{~m} / \mathrm{s}$. The water hammer pressure has a peak 
at approximately $H_{0}^{*}=0.8-1.0$, although the experimental value tends to shift to the lower-water-level side as $P_{0}$ increases. This figure also suggests that a very large water hammer pressure has a potential of being exerted on the structure. For example, at $P_{0}=2.0 \mathrm{MPa}$, a $P_{W H, M A X}$ of about $50 \mathrm{MPa}$ can be exerted when $H_{0}^{*} \approx 0.8$. The $P_{W H, M A X}$ calculated using Eq. (13) also increases in proportion to the 0.5 th power of $\Delta P_{0}\left(P_{W H, M A X} \approx 32.8 \Delta P_{0}^{0.5}\right.$, unit: MPa).

\section{Conclusions}

The experiment was conducted to evaluate the water hammer caused by a rapid gas production due to a watermetal reaction and a steam explosion in a severe LWR accident. A rapid bubble growth was simulated by injecting high-pressure air into a pool of water. The initial water level and injection air pressure were selected as the main experimental parameters. The important results obtained in this study are as follows.

(1) In the selected experimental conditions, the water mass is pushed up with coherency by a growing single bubble until the water level reaches a certain elevation. Afterward, the bubble penetrates the water surface, and then it becomes the water mass group (water mass including small bubbles) and splashes above. The acceleration of the water mass is almost constant.

(2) The dimensionless rising distance of the water mass with coherency $\left(\Delta H_{P}^{*}\right)$ has a peak value at the dimensionless initial water level $\left(H_{0}^{*}\right)$ of $1.0-1.2$.

(3) The rising velocity of the water mass for a vessel with diameter of $1 \mathrm{~m}$ has a peak value at $H_{0}^{*} \approx 0.8-1.0$. The maximum water hammer pressure in this rising velocity is estimated to be about $50 \mathrm{MPa}$ for an injection air pressure of 2.0 MPa.

(4) Experimental correlations which predict the elevated distance and velocity of the rising water mass with coherency were proposed. These correlations can quantitatively evaluate the water hammer pressure that may be exerted on the structure.

To apply the water hammer evaluation method proposed in this report to the analysis of actual reactor, the following subjects remain. Though air was used as the generating gas in this experiment, a condensable gas is generated in an actual steam explosion. The proposed correlation for moving water mass with coherency has not been sufficiently checked for a broad range of size. The applicability and generalization of the proposed method will be improved through future experiments scheduled using a condensable gas (steam) and a model containment vessel of $2.0 \mathrm{~m}$ inside diameter.

\section{Acknowledgments}

This study was financially supported by the Budget for Nuclear Research of the Ministry of Education, Culture, Sports, Science and Technology, with the screening and counseling by the Atomic Energy Commission.

\section{References}

(1) Nuclear Safety Commission of Japan, Accident Management as the Severe Accident Measures in a Power Light Water Reactor Plant, (in Japanese), (1992).

(2) Nuclear Safety Research Association, The Guideline on the Consideration of the Severe Accident in the Containment Vessel of an Advanced Reactor, (in Japanese), (1999).

(3) The Special Expert Committee in the Atomic Energy Society of Japan for the Severe Accident Thermal Hydraulics Phenomenon Evaluation, Report of the Severe Accident Thermal Hydraulics Phenomenon Evaluation, (in Japanese), (2001).

(4) Basu, S. and Ginsberg, T., Ed., Proc. of the Second Steam Explosion Review Group (SERG-2) Workshop, NUREG-1524, Aug., (1996).

( 5 ) Kato, M., Nagasaka, H., Vasilyov, Y., Kolodeshnikov, A. and Zhdanov, V., COTELS Project (2): Fuel Coolant Interaction Tests under Ex-Vessel Conditions, Proc. of OECD Workshop on EX-Vessel Debris Coolability, Karlsruhe, (1999).

( 6 ) Magallon, D. and Huhtiniemi, I., Corium Melt Quenching Tests at Low Pressure and Subcooled Water in FARO, Nuclear Eng. and Design, Vol.204 (2001), pp.369-376.

( 7 ) Yamano, N., Murayama, Y., Kudo, T., Hidaka, A. and Sugimoto, J., Phenomenological Studies on MeltCoolant Interactions in the ALPHA Program, Nuclear Eng. and Design, Vol.155 (1995), pp.369-389.

( 8 ) Song, J.H., Hong, S.W., Kim, J.H., Chang, Y.J., Shin, Y.S., Min, B.T. and Kim, H.D., Insights from the Recent Steam Explosion Experiments in TROI, J. of Nuclear Science and Technology, Vol.40, No.10 (2003), pp.783-795.

(9) The Japan Soc. of Mechanical Engineers, Ed., Handbook of Gas-Liquid Two-Phase Flow Technology, (in Japanese), (1995), pp.229-244, CORONA Publishing Co. 